\title{
A ESTRATÉGIA COMO PRÁTICA UTILIZADA NO RECONHECIMENTO DE UM CURSO DE GRADUAÇÃO PELO MEC
}

\author{
STRATEGY AS PRACTICE USED IN RECOGNITION \\ OF A GRADUATE COURSE BY MEC
}

Recebido: 01/05/2013

Aceite: 02/07/2013

Aleksander Roncon ${ }^{1}$

Tarcita Cabral Ghizoni de Sousa ${ }^{2}$

Indiara Beltrame ${ }^{3}$

Rosália Aldraci Barbosa Lavarda ${ }^{4}$

\section{RESUMO}

O strategizing é uma abordagem teórica que compreende a realização das estratégias por meio da conexão das práxis realizadas pelos praticantes que apresentam tipos de comportamentos orientados pelas práticas sociais (JARZABKOWSKI et al., 2007). O objetivo deste estudo é verificar como a estratégia é desenvolvida, na prática, para o reconhecimento de um curso de graduação pelo MEC. Para tanto, propõ-se: (i) identificar as práticas estratégicas adotadas na organização; (ii) verificar como a práxis acontece nos diferentes níveis organizacionais; e (iii) analisar como os praticantes participam da estratégia como prática. A abordagem da pesquisa é qualitativa. O estudo é realizado em uma faculdade de caráter privado, localizada no norte do Paraná. Utiliza-se um roteiro de entrevista semiestruturado, com questões abertas, análise de documentos e observação direta, como técnicas de coleta de dados, propiciando a triangulação dos dados coletados. Para a análise dos dados coletados, adota-se a técnica de Exame de Padrão de Comportamento (PÉREZ-AGUIAR, 1999). Os resultados encontrados destacam a necessidade de um alinhamento entre os três elementos desenvolvidos no trabalho de Jarzabkowski et al. (2007) e ressaltam a existência do eixo da gestão ambiental como linha transversal a todo projeto pedagógico dos cursos oferecidos, exigência do MEC.

Palavras-chave: Estratégia como prática; Reconhecimento de curso; Gestão ambiental.

${ }^{1}$ Possui graduação em Administração pela Faculdade de Administração de Assis, especialização em Desenvolvimento Gerencial e Gestão da Qualidade e Gestão Empresarial pelo Instituto Brasileiro de Estudos e Pesquisas Sócio-Econômicos e mestrado em Administração pelo Centro Universitário Salesiano - UNISAL. Atualmente é doutorando em Ciências Contábeis e Administração pela Fundação Universidade Regional de Blumenau - FURB. Londrina, Paraná, Brasil. E-mail: kroncon@hotmail.com.

${ }^{2}$ Possui graduação em Ciências Contábeis pela Universidade do Contestado e mestrado em Engenharia de Produção pela Universidade Federal de Santa Catarina - UFSC. Atualmente é doutorando em Ciências Contábeis e Administração pela Universidade Regional de Blumenau - FURB, Blumenau, Santa Catarina, Brasil. E-mail: tarcita@brturbo.com.br.

${ }^{3}$ Possui graduação em Administração Habilitação Comércio Exterior e especialização em Comércio Exterior - Negócios Internacionais pela Universidade Regional Integrada do Alto Uruguai e das Missões - URI. Atualmente é mestranda em Administração pela Universidade Estadual de Londrina - UEL. Londrina, Paraná, Brasil. E-mail: profaindiarabeltrame@hotmail.com.

${ }^{4}$ Possui graduação em Administração pela Universidade Federal de Santa Maria - UFSM, especialização em Administração pela Universidade Regional Integrada do Alto Uruguai e das Missões - URI, mestrado em Organización y Dirección de Empresas pela Universidad Del Museo Social Argentino - UMSA e doutorado em Dirección de Empresas, Estrategias y Organización, pela Universitat de València - UV. Atualmente é professora e pesquisadora da Universidade Federal de Santa Catarina, UFSC, Florianópolis. Santa Catarina, Brasil. E-mail: rosalia.lavarda@ifc.edu.br. 


\section{ABSTRACT}

The strategizing is a theoretical approach that includes the implementation of strategies by connecting the practice performed by practitioners who have types of behaviors driven by social practices (Jarzabkowski et al., 2007). The aim of this study was to determine how the strategy is developed in practice for the recognition of an undergraduate degree at MEC. For both: (i) identify the strategic practices adopted in the organization, (ii) verify how the practice happens at different organizational levels and (iii) analyze how practitioners participating in the strategy as practice. The research approach is qualitative. The study was conducted in a private college of character located in northern Paraná. We used a semi-structured interview structured with open questions, document analysis and observation, and data collection techniques, providing triangulation of data collected. For the data analysis we adopted the technique Exam Pattern of Behavior (PÉREZ-AGUIAR, 1999). The results highlight the need for alignment between the three elements developed in the work Jarzabkowski et al. (2007), and emphasize the existence of the axis of environmental management across the entire line as pedagogical courses offered, as a requirement of MEC.

Keywords: Strategy as practice; Recognition of course; Environmental management.

\section{INTRODUÇÃO}

A oferta de cursos superiores em faculdade ou instituição equiparada depende de autorização do Ministério da Educação (MEC). O reconhecimento de curso é condição necessária, juntamente com o registro, para a validade nacional dos respectivos diplomas. A instituição protocola pedido de renovação e/ou de reconhecimento ao final de cada ciclo avaliativo, junto à Secretaria competente, devidamente instruído, no prazo previsto. (LEGISLAÇÃO DO ENSINO SUPERIOR, 2007). A partir desse momento, por meio de agendamento do MEC, avaliadores cadastrados avaliam in loco a instituição.

Toda instituição que passa pela avaliação do MEC desenvolve uma estratégia para obter sucesso no processo avaliativo. Rese, Canhada e Casali (2008) citam que o processo de formulação e implementação da estratégia como uma construção organizacional é pautado na interação entre os atores envolvidos, as suas práticas discursivas e as suas ações individuais e coletivas no âmbito organizacional. Estudos contemporâneos sobre o tema corroboram que a estratégia como prática é a responsável pela verdadeira vantagem estratégica (BALOGUN et al., 2003).

O olhar sociológico da estratégia (WHITTINGTON, 2007) preocupa-se com os papéis exercidos por seus interlocutores no exercício desta e desloca o papel antes central da economia para a compreensão da estratégia como prática social.

Contemplar a estratégia como prática socialmente construída acaba por impor sérios desafios à cúpula organizacional (MACIEL, 2007, p.13). Aos gerentes de alto escalão caberia a função de utilizar as práticas organizacionais a seu favor, no sentido de moldar a atividade de forma coletiva, em direção à consecução das atividades estratégicas orientadas a determinados objetivos (MACIEL, 2007).

A estratégia, na prática, considera as atividades práticas desenvolvidas no cotidiano da organização, avaliando-a como o modo de agir socialmente empregado pelos atores, o qual conduz à obtenção dos resultados previamente estabelecidos (JARZABKOWSKI et al., 2007). Assim, elabora-se a seguinte questão de investigação: como a estratégia é desenvolvida, na prática, para o reconhecimento de um curso de graduação pelo MEC? Nesse sentido, este estudo tem por objetivo verificar como a estratégia é desenvolvida, na prática, para o reconhecimento de um curso de graduação pelo MEC. Mais especificamente, buscou-se evidenciar como a estratégia acontece, considerando os três elementos do modelo teórico de Jarzabkowski et al. (2007). 


\section{REVISÃO BIBLIOGRÁFICA}

Atualmente, o foco dos estudos sobre estratégia recai sobre a perspectiva da estratégia como prática, ou strategizing (JARZABKOWSKI, 2003, 2004, 2005; BALOGUN et al., 2003; JOHNSON et al., 2003; REGNER, 2003, 2008; WHITTINGTON, 2006; JARZABKOWSKI et al., 2007; JARZABKOWSKI e SPEE, 2009). A estratégia como prática apresenta uma nova perspectiva para a compreensão da estratégia realizada por meio de atores organizacionais e suas interações sociais (WHITTINGTON, 2002).

A estratégia deve ser implementada por todos os atores da organização envolvidos com sua prática, e não apenas por aqueles que ocupam cargos no topo da pirâmide (JARZABKOWSKI; BALOGUN e SEIDL, 2007). Jarzabkowski (2003) explica que a estratégia como prática (strategizing) busca compreender o modo como os atores concebem a estratégia a partir de suas interações sociais com outros atores, visto que eles emprestam uma visão sociológica para a estratégia e a consideram como algo profundamente arraigado, realizado no âmbito social (WHITTINGTON, 2007).

Assim, entende-se que o strategizing é composto por um grupo de atores interdependentes (WHITTINGTON et al., 2003), que realizam atividades consideradas estratégicas na medida em que os resultados de suas ações contribuem para a sobrevivência e para a vantagem competitiva da organização (JOHNSON; MELIN; WHITTINGTON, 2003). No momento que essas atividades passam a trazer resultados à organização, são consideradas como uma estratégia prática, mesmo que não tenham sido planejadas e elaboradas formalmente (JARZABKOWSKI et al., 2007).

A estratégia deve ser vista, cada vez mais, na visão de Jarzabkowski (2004), como algo a ser feito, como uma prática vista por meio da mistura de ação e direção, na qual o conhecimento adquirido com essa interação faz com que a estratégia aconteça. Ainda, de acordo com o autor, as atividades estratégicas são desenvolvidas, na prática, como um sistema de atividade composto por principais agentes, estruturas coletivas e atividades práticas, conforme Figura 1.

Jarzabkowski (2003) argumenta que a estratégia como prática ressalta as interações entre os intervenientes e seu contexto. As práticas estratégicas habilitam a interação entre as diferentes partes da organização, na construção da atividade estratégica compartilhada.

Figura 1 - Sistema de Atividade em que a Estratégia como Prática ocorre.

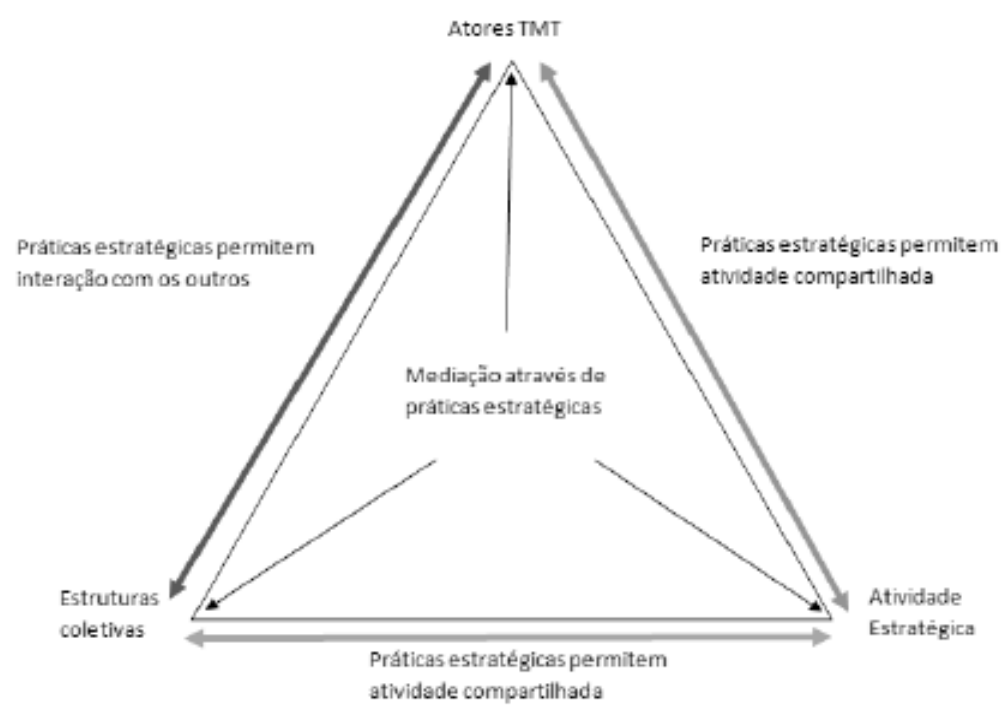

Fonte: Jarzabkowski (2003, p. 25). 
Em seguida, Whittington (2006) apresenta três conceitos que constituem a integração da estratégia como prática e enfatiza a necessidade de se entender como o processo de strategizing é desenvolvido e divulgado, tanto dentro como fora das organizações. A estratégia é interpretada, de acordo com Whittington (2006), por meio da interação entre os temas práxis, práticas, praticantes. $\mathrm{O}$ autor define a práxis como o fluxo de atividade desenvolvida pelas pessoas, as práticas como a rotina do comportamento, incluindo tradições, normas e procedimentos, e praticantes - como os profissionais responsáveis em exercer as práticas.

As práticas, para Jarzabkowski et al. (2007), podem ser definidas como "tipos de comportamentos que são constituídos por vários elementos" (JARZABKOWSKI et al., 2007, p. 9). As práticas são os hábitos, artefatos e modos de agir socialmente definidos, por meio do qual o fluxo de atividade estratégica é construído (WHITTINGTON, 2001). A práxis se refere à interconexão das ações dos diferentes atores organizacionais e grupos dispersos que estão envolvidos com a organização e que contribuem para esta (WHITTINGTON, 2007). A práxis é "a atividade estratégica realizada, a operacionalização prática em diferentes níveis de análise que estão interligados ao longo do tempo" (JARZABKOWSKI et al., 2007, p. 9). Os praticantes são os participantes ativos na construção das atividades, que são uma consequência para a organização e sua sobrevivência (JARZABKOWSKI et al. 2007, p. 10). Os atores organizacionais apresentam formas particulares de linguagem em suas práticas sociais, e, apesar de ocorrer a rotinização dessas práticas, elas não são imutáveis, são combinadas e alteradas de acordo com seu desenvolvimento (JARZABKOWSKI, BALOGUN e SEIDL, 2007; GOLSORKHI et al., 2010; LAVARDA et al, 2010). Conforme ilustrado na Figura 2, a consideração desses três elementos leva à outra implicação da estratégia como prática: relacionar os níveis intraorganizacional, organizacional e extraorganizacional (JOHNSON et al., 2007).

Figura 2 - Integração da práxis, práticas e profissionais praticantes

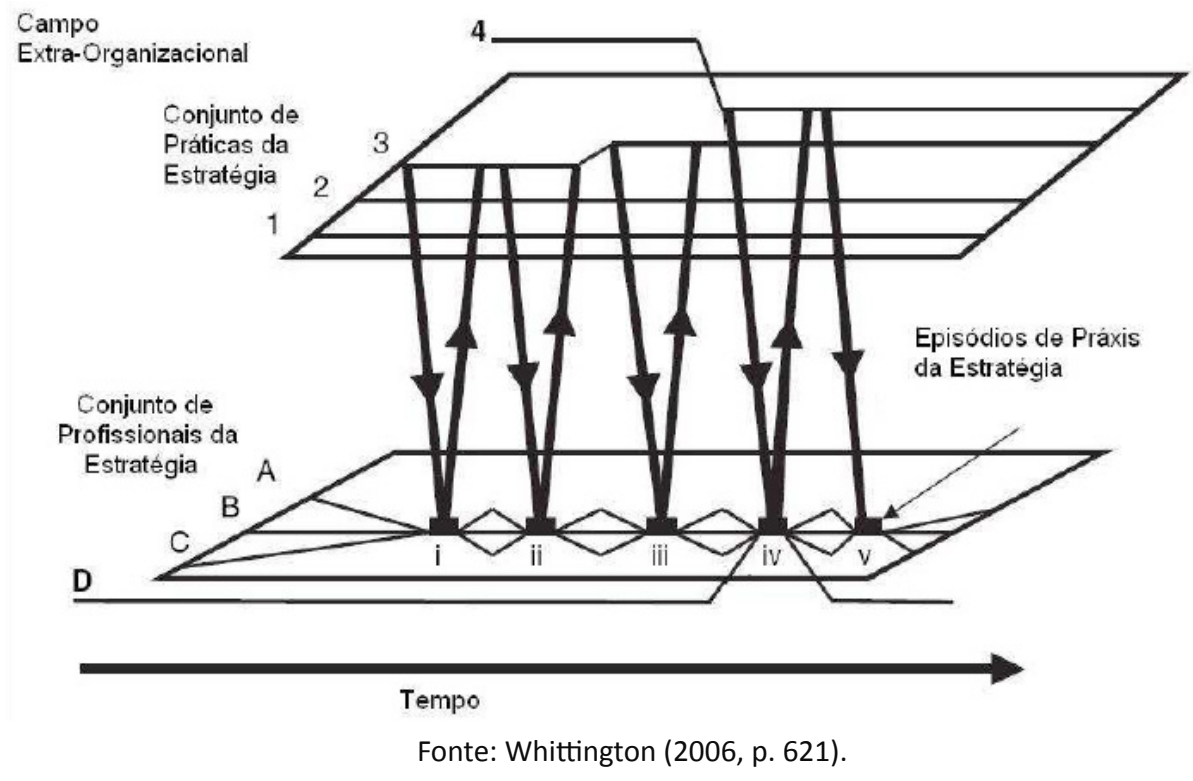

Os estudos em estratégia como prática tanto investigam as atividades internas e suas consequências para as organizações, quanto identificam práticas advindas do ambiente externo à organização (WHITTINGTON; JOHNSON; MELIN, 2004). Ações no nível micro precisam ser entendidas em seu contexto social mais amplo: os atores não agem isoladamente, mas utilizam os modos socialmente definidos de agir, os quais surgem das instituições sociais plurais às quais pertencem (JARZABKOWSKI; BALOGUN; SEIDL, 2007). 
O conjunto de práticas da estratégia representadas pelos números 1, 2, 3 e 4 é estipulado pelos gestores e praticado pelo conjunto de profissionais da estratégia descritos pelas letras A, B e C (nível intraorganizacional) e D (nível extraorganizacional). À medida que as estratégias são colocadas em prática, os gestores conseguem avaliar o que realmente ocorre na práxis, bem como analisar o que é necessário para aperfeiçoar essas estratégias (WHITTINGTON, 2006). O autor explica que os profissionais da estratégia, os praticantes, são os nomeados de " $A$ " a " $D$ ", formados por membros da alta direção, por gerentes de nível médio (middle manager) e por pessoas externas à organização.

Por fim, os estudos de Jarzabkowski et al. (2007) forneceram um quadro conceitual, no qual o processo de realização da estratégia pode ser analisada por meio das ligações entre os elementos práticas, práxis e praticantes. Esses elementos são os focos de análise para melhor compreensão do strategizing, havendo uma necessidade de serem explorados mais profundamente (JARZABKOWSKI et al., 2007).

Os elementos que compõem o strategizing estão ilustrados na interconexão da Figura 3, na ligação entre praticantes e práxis (C) e entre a prática e os profissionais (B) (JARZABKOWSKI et al., 2007).

Figura 3 - Uma estrutura conceitual para analisar a estratégia como prática.

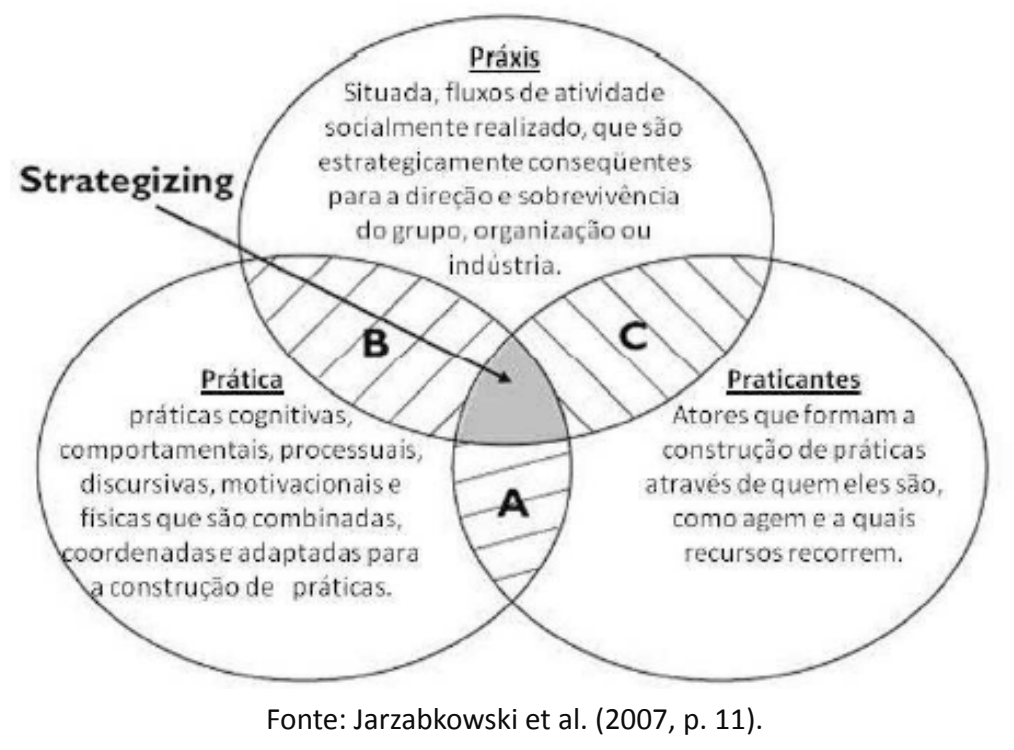

O strategizing é o resultado do processo de formação da estratégia, que explica como as estratégias são realizadas, uma abordagem teórica que compreende a realização das estratégias por meio da interconexão das práxis realizadas pelos praticantes que apresentam tipos de comportamentos orientados pelas práticas sociais (WHITTINGTON, 2006; JARZABKOWSKI et al., 2007; RÉGNER, 2008). As práticas orientam as atividades estratégicas por meio de comportamentos individuais, processos racionais e práticas sociais.

As práticas podem ser definidas como os processos, os comportamentos, as cognições, recursos discursivos e físicos, de modo, que "múltiplos atores são capazes de interagir, a fim de socialmente realizar a atividade coletiva"; orientam a atividade, normas, procedimentos, comportamentos, etc. (JARZABKOWSKI et al., 2007, p. 9). 
As práticas são as ferramentas de estratégia, isto é, as coisas feitas, tanto no sentido de aceitas como legítimas, quanto no de praticadas por meio de repetições feitas no passado, e os praticantes, ou seja, os estrategistas (WHITTINGTON, 2002). A práxis é desenvolvida por meio de estratégias previamente estabelecidas (estratégias deliberadas) e/ou por meio da participação dos atores organizacionais (estratégias emergentes), sendo a estratégia colocada em prática, ou seja, uma consequência do processo de formação da estratégia. Jarzabkowski et al. $(2007$, p. 9) definem a práxis como a atividade estratégica realizada, a operacionalização prática em diferentes níveis de análise que estão interligados ao longo do tempo, é a atividade em si. Os praticantes são o foco central deste processo de construção das atividades. Eles são responsáveis por moldar a atividade estratégica através do que eles são e de como agem (JARZABKOWSKI et al., 2007, p. 10).

\section{MÉTODO DE PESQUISA}

Quanto à abordagem, este estudo é considerado qualitativo. Segundo Vieira e Zouain (2004), o método garante a riqueza dos dados, permite ver um fenômeno na sua totalidade, bem como facilita a exploração de contradições e paradoxos. A metodologia qualitativa é mais adequada para contestar questões que requerem uma descrição, interpretação e explicação mais detalhada sobre o fenômeno a ser estudado, o que também justifica a caracterização desta pesquisa como explicativa, já que tem como objetivo verificar como ocorre o processo de formação da estratégia (BALBASTRE, 2003).

No que tange a seleção do caso, o estudo se realiza em faculdade de caráter privado, localizada no norte do Paraná, para preservar a imagem da faculdade não foi citado seu nome. A seleção do caso foi não aleatória, intencional e por acessibilidade (EISENHARDT, 1989). Essa seleção se justifica pela participação dos pesquisadores na instituição, o que propicia o conhecimento de todos os grupos sociais de forma ampla e, em profundidade, o conhecimento de suas políticas, cultura, história e de seu ambiente (GODOY, 1995).

Os estudos de caso, em geral, "[...] representam a estratégia preferida quando se colocam questões do tipo 'como' e 'por que', quando o pesquisador tem pouco controle sobre os acontecimentos e quando o foco se encontra em fenômenos contemporâneos inseridos em algum contexto da vida real" (YIN, p. 19, 2005).

Como técnica de coleta de dados, foram utilizadas entrevista semiestruturada, análise de documentos e observação direta. Foram entrevistados o diretor acadêmico, o coordenador acadêmico do curso, um professor e um aluno da instituição, esses foram os sujeitos sociais da pesquisa, considerados os respondentes envolvidos no desenvolvimento da prática estratégica da faculdade. Utilizou-se um roteiro de entrevista semiestruturado, composto por questões abertas, as quais permitiram maior riqueza de detalhes nas respostas, maior participação e conhecimento da realidade dos entrevistados e que atenderam aos objetivos propostos. $O$ roteiro de entrevista se baseou em questões resultantes do marco teórico revisado. As entrevistas foram gravadas e posteriormente transcritas. Os dados da transcrição serviram de base para a análise dos dados. Cada entrevista teve a duração média de trinta minutos.

A análise de documentos envolveu manuais, formulários, plano de desenvolvimento institucional (PDI) e projeto pedagógico do curso (PPC), contendo a missão, a visão e os valores praticados pela faculdade. A análise documental possibilitou a verificação dos processos que representam a identidade organizacional da instituição pesquisada. Utilizou-se também a observação direta, por meio da participação em reuniões, prestando atenção à cultura e ao modus operandis da IES in locus. Foi utilizado um bloco de notas para registrar as observações realizadas, 
permitindo a comparação com as demais fontes de evidências, oportunizando a triangulação dos dados, a qual evita o viés potencial de uma única fonte de dados e auxilia na construção de análises mais completas e precisas, por meio da convergência das fontes de evidência (EISENHARDT, 1989; YIN, 2005).

Para a análise dos dados coletados, foi adotada a técnica de Exame de Padrão de Comportamento (EPC) (PÉREZ-AGUIAR, 1999), que consiste no confronto dos documentos internos da faculdade, os resultados das entrevistas e a observação direta com o que é apresentado na literatura. Assim, passa-se a descrever como ocorre o processo de estratégia, detalhando todos os procedimentos adotados nas suas concepções, com o objetivo de entender como elas acontecem na prática.

\section{ANÂLISE E DISCUSSÃO DOS RESULTADOS}

Neste capítulo, apresenta-se a análise dos dados com intuito de responder os objetivos propostos neste estudo. No sentido de preservar a identidade da empresa analisada, Ihe foi atribuído o nome de "Faculdade Beta". A identidade dos dirigentes e colaboradores também foi preservada.

\subsection{Caracterização da Instituição}

A Faculdade Beta, com sede em Londrina/PR, iniciou suas atividades em 2002, com foco na proposta acadêmica de ministrar o ensino em seus variados níveis do conhecimento, bem como investir em pesquisa e extensão. Em outubro de 2010, o MEC agendou a avaliação in loco para o reconhecimento do curso de graduação em administração e a instituição desenvolveu uma estratégia para obter sucesso no processo avaliativo, partindo do conjunto formado por missão, visão e valores da Faculdade Beta, que representa sua identidade organizacional, a essência do que ela é, o que almeja ser e os valores que a norteiam.

A Faculdade Beta tem como missão contribuir para a formação de profissionais competentes, éticos, responsáveis e empreendedores, por meio da transmissão e geração de conhecimentos que possam atuar em beneficio da sociedade. Ela pretende ser referência em educação, gerando, em seus alunos, colaboradores e parceiros, um sentimento de admiração e orgulho por fazerem parte de uma organização que, pela sua atitude, inspira e motiva outras. Para tanto, esta faculdade pratica valores como respeito à integralidade humana, responsabilidade socioambiental, busca contínua de aprendizagem, solidariedade, bem como respeito à diversidade.

Reconhecendo a crescente importância do conhecimento para a formação de cidadãos e para o processo de desenvolvimento da sociedade, a Faculdade Beta tem buscado articular o ensino com a realidade social, econômica, política e com a cultural local, buscando compreender melhor e mais profundamente a realidade em que seu egresso irá atuar e contribuir para sua transformação. Desde sua origem, a instituição procurou assumir um compromisso com o desenvolvimento da região, para ser um centro transformador da estrutura cultural de sua área de intervenção. A Faculdade Beta também considera relevante a existência da sustentabilidade como linha transversal a todo projeto pedagógico dos cursos oferecidos.

Por fim, cabe destacar que a Faculdade Beta acredita em um processo de formação do profissional que deve abranger uma série de compromissos com a realidade social enquanto sujeito partícipe de sua construção qualitativa, ao mesmo tempo em que assumirá o exercício profissional na direção da resolução dos problemas locais e regionais que visam a atender os objetivos da gestão sustentável. 


\subsection{Análise das Categorias Analíticas}

A análise das categorias analíticas tem como base os conceitos estabelecidos na fundamentação teórica deste estudo, e estes se dividem em práticas, práxis e praticantes. Os entrevistados são o diretor acadêmico, o coordenador acadêmico do curso, um docente e um discente da instituição.

\subsubsection{Categoria de Análise - Práticas}

As práticas orientam as atividades do dia a dia (WHITTINGTON, 2006). As práticas podem ser associadas ao processo que orienta o colaborador no desenvolvimento das atividades. Assim, verificou-se que a diretoria acadêmica participa neste processo, de modo a coordenar, orientar e instruir os colaboradores na execução das atividades para o reconhecimento do curso. O coordenador acadêmico relata:

O diretor acadêmico foi o responsável pela coordenação das atividades da instituição como um todo, suprindo a equipe com as informações necessárias para que as atividades propostas fossem realizadas de modo eficaz. Ele funcionou como um facilitador da provisão destes dados, e seu trabalho foi primordial para a obtenção do conceito obtido pelo curso de graduação em administração junto ao MEC (ENTREVISTA, COORDENADOR ACADÊMICO)

O diretor acadêmico afirma ter feito uso de informações contidas em documentos importantes da instituição para formular sua estratégia:

A minha estratégia teve início com a leitura adequada de cada documento da instituição. A leitura detalhada do PDI - Plano de Desenvolvimento Institucional, bem como a participação da construção deste instrumento, depois uma leitura detalhada do PPC Projeto Pedagógico do Curso de administração me auxiliaram na busca para o caminho certo de condução da minha equipe (ENTREVISTA, DIRETOR ACADÊMICO).

O diretor acadêmico explica que o PDI é o instrumento de planejamento e gestão que considera a identidade da Instituição de Ensino Superior (IES), no que diz respeito a sua filosofia de trabalho, à missão a que se propõe, às estratégias para atingir suas metas e seus objetivos, a sua estrutura organizacional, ao Projeto Pedagógico Institucional com as diretrizes pedagógicas que orientam suas ações e as atividades acadêmicas que desenvolve ou que pretende desenvolver. Ele explica, também, que o PPC é o documento orientador de cada curso, que traduz as políticas acadêmicas institucionais. E continua:

Participei, também, do preenchimento do instrumento utilizado na base do sistema e-MEC e, ao fazer isso, acabei por conhecer melhor o roteiro que seria utilizado pelos avaliadores do MEC na visita in loco. A partir do aprofundando do conhecimento necessário para conduzir minha equipe para uma boa avaliação, determinei o processo que iria nortear minha equipe no desenvolvimento das atividades (ENTREVISTA, DIRETOR ACADÊMICO).

O diretor acadêmico explica que o próximo passo foi repassar ao coordenador os documentos previamente analisados. Percebe-se, na rotina da instituição, o perfil analítico dos colaboradores, que contribui para que as atividades propostas sejam executadas de modo eficaz.

As rotinas organizacionais socialmente definidas contribuem para a formação de um processo continuo de atividades (JARZABKOWSKI, 2003; JARZABKOWSKI, 2005, JARZABKOWSKI et 
al., 2007), sendo realizadas por meio da interação dos diversos atores organizacionais. Percebese, por meio da fala dos atores entrevistados, que uma das práticas utilizadas para a obtenção da nota máxima na avaliação do curso de administração da Faculdade Beta envolveu a rotina de análise de uma série de documentos. Essa variável pode ser identificada em diferentes atores da instituição, como, por exemplo, na forma como o coordenador do curso explica que:

[...] a estratégia adotada por mim partiu da análise detalhada de cada dimensão contida no instrumento utilizado pelo MEC para proceder à avaliação de cursos de graduação. Esse instrumento foi obtido junto ao Sistema Nacional de Avaliação da Educação Superior (SINAES) e subdivide-se em: dimensão 1 - organização didático pedagógica; dimensão 2 - corpo docente; e dimensão 3 - instalações físicas (ENTREVISTA, COORDENADOR ACADÊMICO).

O padrão de adequação que se forma dessa sequência de ações diárias (JARZABKOWSKI, 2003) possibilita à organização alcançar seus objetivos, uma vez que essas ações são construídas e reconstruídas continuamente, formando novos padrões, e o resultado desse processo de interação é a estratégia realizada. Pode-se, ainda, observar essa prática no seguinte depoimento do coordenador:

Tive a oportunidade de conduzir a construção do PPC que é o documento composto pelos conhecimentos e saberes necessários à formação das competências estabelecidas a partir do perfil desejado para o nosso egresso. Dividi esta tarefa com um corpo docente qualificado que contribuiu para que a estrutura e o conteúdo curricular, bem como o ementário e as bibliografias básica e complementar funcionassem como estratégias de ensino que apoiassem o pleno funcionamento do curso (ENTREVISTA, COORDENADOR ACADÊMICO).

O padrão analítico percebido na rotina dos entrevistados, por meio da fala do diretor acadêmico e do coordenador do curso, pode ser observado também no depoimento da docente entrevistada, quando destaca que realmente há necessidade de concatenação no grupo de trabalho, conforme é evidenciado abaixo:

Todas as vezes que fui convidada para colaborar na construção do PPC ou nas atividades para a visita do MEC, uma série de documentos me foi entregue para que eu pudesse entender a filosofia do trabalho que estava sendo proposto. Uma das características do trabalho do coordenador é começar uma atividade somente quando todos os envolvidos têm conhecimento das variáveis envolvidas no processo. Eu costumo brincar que na Faculdade Beta os professores tem sempre lições de casa (ENTREVISTA, DOCENTE).

As práticas estratégicas ocorrem no momento em que toda a equipe se mobiliza, unindo seus conhecimentos para proporcionar a organização o alcance da vantagem competitiva. Outro ponto a ser considerado como prática da Faculdade Beta é o bom relacionamento da equipe, visto que gera uma cultura amistosa e contribui com o desenvolvimento das atividades diárias. $O$ diretor acadêmico relata:

Acredito ser importante criar um bom relacionamento com todos os membros da equipe envolvidos no projeto. Considero este um ponto forte, que eu procuro sempre desenvolver, uma vez que um bom relacionamento se reflete em motivação, cooperação e no desejo de dar o seu melhor, e isso foi bastante importante neste processo. Se a equipe não tivesse essa coesão, acredito que o resultado não teria sido tão significativo como foi. Sempre que posso, eu procuro estimular essa coesão para que ela aconteça. Participando, trabalhando junto, defendendo a equipe de maneira geral. Acredito que resultado da coesão da equipe refletiu na presteza de provisão das informações para os avaliadores (ENTREVISTA, DIRETOR ACADÊMICO). 
O clima de relacionamento amistoso entre os colaboradores pode ser verificado no discurso do coordenador:

Eu acredito que o bom relacionamento seja um pré-requisito para qualquer ambiente de trabalho, visto que um relacionamento amistoso contribui, de forma significativa, com o bom andamento das atividades. Talvez por ser da área de pessoas eu tenha este valor fortemente arraigado. De uma maneira geral, todos nós lidamos com pessoas, com alunos, professores e funcionários e toda vez que alguém quebre esta corrente harmoniosa acaba contaminando os outros e fazendo com que o ambiente de trabalho se torne desagradável, desmotivador, com ambientes acirrados, grupos de pessoas que defendem uma pessoa em detrimento de outras. O clima torna-se ruim de uma maneira geral (ENTREVISTA, COORDENADOR ACADÊMICO).

O diretor acadêmico revela que, por conta dessa característica do coordenador do curso, havia uma afinidade muito grande entre ele e os docentes. De acordo com o diretor acadêmico:

Esta afinidade acabou se revelando uma excelente estratégia para a avaliação do curso, visto que os professores depositaram, no coordenador, a confiança necessária para o desenvolvimento das atividades relacionadas com o reconhecimento do curso. A avaliação despertou, na equipe, um senso ainda maior de união, e o papel decisivo para a obtenção da nota máxima ficou por conta da coordenação, que teve um comportamento de pacificação, de resolução de conflitos, de desenvolvimento pessoal de toda a comunidade acadêmica. E isso, de fato, refletiu-se na avaliação (ENTREVISTA, DIRETOR ACADÊMICO).

Para se entender como ocorre a percepção das práticas estratégicas, é necessário entender como os atores organizacionais constroem e reconstroem significados e de que forma eles compartilham e interpretam tais significados. Nesse sentido, Machado (2004) salienta que os ambientes aos quais as organizações estão inseridas são difusores de elementos culturais, tais elementos são utilizados para definir uma linguagem comum para toda a organização (MACHADO-DA-SILVA; FONSECA; FERNANDES, 1999; MACHADO, 2004). Este ambiente amistoso reflete o bom relacionamento dos membros da equipe de modo geral. A docente confidencia que:

Na hora do intervalo, a sala dos professores se transforma em um ambiente de integração que considero importante. É um momento em que os professores trocam experiências sobre as turmas, ajudam-se na solução de situações-problema relacionadas ao sistema acadêmico e batem um papo descontraído. Arrisco a dizer que, no intervalo, nós temos um momento festivo (ENTREVISTA, DOCENTE).

Considerando o depoimento dos entrevistados, evidencia-se que a prática da análise aprofundada dos documentos denota uma preocupação com a manutenção das regras e dos procedimentos padronizados. $O$ bom relacionamento entre os colabores da instituição pode ser entendido como fator que contribui de modo relevante para o alcance das metas da instituição, visto que tal comportamento se apresenta na estratégia como prática.

\subsubsection{Categoria de Análise - Práxis}

A práxis é a forma como o colaborador executa a ação, ou seja, é o como fazer do praticante, que é relevante porque modifica ou caracteriza a ação, fazendo uma adaptação entre a estratégia existente e as particularidades que ocorrem no dia a dia da empresa (WHITTINGTON, 2006; JARZABKOWSKI, et al., 2007). Dessa forma, a práxis pode ser observada por meio de relatos das ações presentes no discurso do diretor acadêmico: 
Considero a maior estratégia praticada pela faculdade desenvolver um trabalho sério durante todo o curso. O instrumento utilizado pelo MEC para avaliar os cursos é um instrumento detalhado, que esmiúça todas as particularidades da instituição, que busca o que já foi realizado, a coerência entre o que foi proposto no Plano de Desenvolvimento Institucional e o que efetivamente foi realizado. Se não tivéssemos a postura de seguir o que o MEC estabelece, certamente a nota não seria a que foi obtida. Então, eu acredito que o modo responsável como o curso foi conduzido desde o início refletiu de forma positiva no resultado excepcional obtido pela faculdade (ENTREVISTA, DIRETOR ACADÊMICO).

As práticas estratégicas são resultado das tradições, normas, regras, rotinas, e procedimentos padronizados (institucionalizados) da organização, tem estreita relação com os padrões de interação e interpretação envolvidos na atividade estratégica (JARZABKOWSKI et al., 2007).

Quando fui convidado para assumir a coordenação do curso, ficou clara a preocupação dos dirigentes da instituição com o cumprimento das regras e normas rigorosas estabelecidas pelo MEC. Durante os anos que estou à frente da coordenação, sempre procurei seguir o que foi proposto, alinhando o PDI com o PPC e respeitando as diretrizes estabelecidas pelo MEC. De fato, seguir tais regras criou uma rotina que facilitou meu trabalho na hora do reconhecimento do curso (ENTREVISTA, COORDENADOR ACADÊMICO).

Jarzabkowski et al. (2007) explicam, ainda, que os diversos atores organizacionais são capazes de interagir segundo normas pré-estabelecidas, a fim de socialmente realizar a atividade compartilhadas. A professora entrevistada explica que:

Todo começo de semestre, o coordenador realiza uma semana acadêmica que, além de tratar de assuntos relacionados com o cotidiano acadêmico (treinamentos, aperfeiçoamentos, entre outros), trata também da importância do trabalho administrativo do professor estar em dia. É-nos reservado, durante a semana, um tempo para lançar os planos de ensino e os diários de classe no sistema. Assim, quando começam as aulas, os alunos têm acesso a essas informações (ENTREVISTA, DOCENTE).

Com o intuito de melhor esclarecer as práxis da instituição, entrevistou-se também um discente que participou do processo de reconhecimento do curso de Administração da Faculdade Beta. Ele explica como ocorrem suas atividades dentro da instituição:

Aqui o negócio é sério. Comecei meu curso em outra instituição e me transferi pra cá há dois anos. No começo, eu estranhei a seriedade de alguns professores, que nunca deixavam a gente sair antes do horário. Estranhei também quando tive que fazer uma prova de segunda chamada no dia que a faculdade estabeleceu, e não em sala, em outro dia, como eu fazia na outra (ENTREVISTA, DISCENTE).

O discente, representante do maior contingente de praticantes da instituição, continua explicando como se dá a estratégia na prática e de modo essa estratégica contribui com o êxito da instituição:

Aqui a gente tem que assistir a todas as aulas, mas tem os professores que são muito bons. Eles não faltam, são amigos e têm compromisso com a gente. Um semestre me descontrolei com as faltas e reprovei, nem adiantou falar com o professor. Então, acho que é isso. Tem outra coisa: não adianta chorar nota, não. Ou você estuda ou você dança. Mas, aos pouquinhos, eu fui entendendo que os caras aqui fazem as coisas do jeito certo. $E$ eu fui me acostumando e gostando. E aprendendo, e valorizando a faculdade (ENTREVISTA, DISCENTE). 
Trabalhar de acordo com normas e regras pré-estabelecidas se tornou uma variável facilitadora no processo de avaliação do curso. A docente relata:

Somos incentivados a trabalhar dentro dos prazos estabelecidos no calendário acadêmico da faculdade. Quando não cumprimos tais prazos, nosso coordenador nos dá um puxão de orelha. Ele sempre nos lembra de que trabalhamos com um sistema acadêmico integrado, e nosso aluno tem, em tempo real, informações de seu desempenho nas disciplinas. Quando deixamos de lançar presenças ou faltas na sequencia da aula ou atrasamos o lançamento de nota, eles nos cobram (ENTREVISTA, DOCENTE).

Outra ação que explica a práxis realizada na instituição pode ser verificada por meio da interpretação das palavras do diretor acadêmico:

Houve a adoção de uma estratégia muito clara de preparar a documentação que seria exigida pelos avaliadores antecipadamente. Então, quando eles vieram para fazer a avaliação, tudo que imaginamos que seria requerido de cada setor da instituição nós deixamos pronto antecipadamente. E, mais do que isso, nós dispusemos tais documentos de uma maneira física, que procurasse facilitar o acesso a essas informações e que contribuísse para o rápido preenchimento do instrumento de avaliação (ENTREVISTA, DIRETOR ACADÊMICO).

O fato de a organização proporcionar o suporte necessário para o melhor desempenho das atividades pode ser percebido por meio da estratégia adotada pelo coordenador do curso:

Após uma análise detalhada de todas as dimensões que compõem o instrumento de avaliação utilizado pelo MEC, desenvolvi minha estratégia para que tudo transcorresse bem durante a visita. Fiz um levantamento dos indicadores e os dividi em três categorias de análise: os que conseguiríamos nota máxima (5); os que conseguiríamos notas entre 4 e 3; e os que conseguiríamos nota inferior a 3. Como a instituição segue a filosofia de trabalhar segundo as recomendações do MEC, aproximadamente $45 \%$ das dimensões analisadas se enquadravam na primeira categoria de análise; $35 \%$, na segunda; e $20 \%$, na terceira categoria. Quando analisei os critérios que seriam utilizados na primeira dimensão do instrumento (organização didática pedagógica do curso), pude verificar que atendíamos a quase todos os requisitos para a obtenção da nota máxima. $O$ indicador que demandava atenção era "o perfil do egresso". Havíamos descrito em nosso PPC como era o perfil desejado dos alunos da Faculdade Beta, mas não sabíamos como os avaliadores iram analisar esse indicador. A segunda dimensão (Corpo Docente) era a mais preocupante, e a terceira (Instalações Físicas) atendia praticamente a todos os critérios de análise para a obtenção da nota máxima (ENTREVISTA, COORDENADOR ACADÊMICO).

Percebe-se que muitas das ações e atividades desenvolvidas no cotidiano da instituição contribuíram de modo significativo para a obtenção da nota máxima. O coordenador explica, ainda, que:

A partir desta análise, dividi minha equipe e comecei a distribuir as tarefas. Os professores se ofereceram voluntariamente para os trabalhos, e cada um foi se ajustando às atividades de acordo com suas competências. Como o Projeto Pedagógico do Curso foi desenvolvido em parceria com os professores da instituição, cada um sabia exatamente quais processos precisava realinhados para a visita in loco. A divisão das tarefas se deu harmonicamente (ENTREVISTA, COORDENADOR ACADÊMICO).

As práxis são ferramentas disponíveis na organização, que auxiliam o desenvolvimento dos processos diários (JARZABKOWSKI et al., 2007), e a legitimação das práticas são aceitas e desempenhadas (práxis) por todos os atores organizacionais (praticantes). A docente explica: 
Dividimos-nos em pequenos grupos, com tarefas claras e objetivas. Nosso grupo é tão unido que, quando os professores de outros grupos terminavam suas tarefas, eles se juntavam a outros grupos para ajudar. Muita coisa acabou sobrando para o coordenador, até porque ele era a pessoa que mais entendia do funcionamento do curso e das diretrizes do MEC. Cansei de ir embora tarde da noite, e ele continuava conferindo toda a documentação para que tudo ficasse de acordo com o instrumento de avaliação do MEC. O conhecimento dele foi fundamental para conseguirmos a nota (ENTREVISTA, DOCENTE).

Entende-se que as atividades desempenhadas pelos colaboradores da Faculdade Beta definem sua práxis, ou seja, o modo como as práticas foram executadas pelos praticantes da estratégia para a obtenção da nota máxima.

\subsubsection{Categoria de Análise - Praticante}

O praticante é o sujeito que executa diariamente uma série de atividades estratégicas compartilhadas de modo repetitivo e, assim, torna-se imprescindível para a realização das estratégias organizacionais (JARZABKOWSKI et al., 2007). O diretor acadêmico relata que, por conta do papel que desempenha na instituição, sua estratégia principal foi trabalhar a motivação da equipe e fazer os apontamentos necessários para os encarregados de cada uma das atividades realizarem suas tarefas.

Jarzabkowski et al. (2007) consideram importante a forma peculiar de agir dos atores frente a diferentes situações que se apresentam na execução das atividades diárias, praticadas de acordo com cada função. $O$ diretor acadêmico explica:

Considero uma grande estratégia a oportunidade aplicar toda a profundidade de conhecimento da equipe durante a avaliação. $O$ trabalho com o coordenador do curso foi um tanto facilitado pelo fato de ele estar completamente integrado ao desenvolvimento do curso desde o começo. Ele é uma pessoa que tem um grande conhecimento e uma boa formação na área. Então, a possibilidade de potencializar a participação de um coordenador que conhecia em profundidade as nuances e os detalhes do curso, somado a sua capacidade de desenvolver um relacionamento adequado e pertinente com o pessoal docente e com a equipe de apoio técnico-administrativo tornou-se, certamente, uma estratégia decisiva na obtenção da nota (ENTREVISTA, DIRETOR ACADÊMICO).

Observa-se que o relacionamento entre colaborador e empresa se torna estratégico à medida que o dinamismo dessa interação produz os resultados esperados, que se transformam em vantagem competitiva, como salienta o coordenador acadêmico:

A instituição sempre disponibilizou os recursos necessários para o desenvolvimento do meu trabalho. Minha melhor estratégia foi realizar, ao longo do funcionamento do curso, um trabalho que cumprisse com rigor as diretrizes contidas tanto no Plano de Desenvolvimento Institucional quanto no Projeto Pedagógico do Curso de administração da Faculdade Beta. Essa postura facilitou o trabalho de todos na preparação da visita do MEC para o reconhecimento do curso. Na visita in loco, meu trabalho consistiu em transmitir a consistência pedagógica e didática dos nossos regimentos, por meio da apresentação dos documentos acadêmicos da instituição, que abarcavam todas as dimensões exigidas pelo MEC. Durante os dois dias de avaliação para o reconhecimento do curso, acompanhei os avaliadores, explicando como os processos da instituição aconteciam na prática. Foram dias de intensa movimentação recompensados com a nota máxima (ENTREVISTA, COORDENADOR ACADÊMICO). 
O coordenador argumenta, ainda, que o bom relacionamento com os professores favoreceu no desenvolvimento das tarefas necessárias para a obtenção da nota máxima.

Sempre que solicitados, cada um, a sua maneira, realizou um trabalho excepcional. 0 resultado final não teria sido o mesmo sem o trabalho em conjunto entre direção, coordenação e docentes. Não podemos deixar de mencionar a importância dos alunos, que defenderam o curso, os professores, a coordenação e a instituição de forma brilhante (ENTREVISTA, COORDENADOR ACADÊMICO).

Percebe-se, na fala do coordenador, a importância do trabalho conjunto dos atores organizacionais empenhados na realização das atividades práticas em prol do alcance dos objetivos organizacionais. A docente relatou:

No momento em que nos reunimos com os avaliadores no auditório da faculdade, dava para perceber um clima de ansiedade no ar. Eles começaram a reunião com algumas perguntas direcionadas a cada professor e, na sequencia, fizeram algumas perguntas abertas. Conforme a conversa foi acontecendo, percebi um clima de segurança entre os professores e, mesmo quando os avaliadores fizeram perguntas mais "capciosas", o pessoal se manteve firme. Dava para perceber a sinergia do grupo no discurso afinado dos professores. Em minha opinião, esse discurso só foi possível porque acreditávamos no que dizíamos. Conseguimos transmitir nossa verdade, e ficou claro que os avaliadores perceberam isso (ENTREVISTA, DOCENTE).

O coordenador explica que o papel dos discentes foi imprescindível para o cumprimento das metas estabelecidas pela instituição. $O$ discente comentou:

Ligaram-me da faculdade e me disseram que o "MEC" queria falar comigo. Liguei para o coordenador para entender o que estava acontecendo, e ele me explicou que os caras tinham escolhido alguns alunos para conversar, e que eu estava na lista. A gente entrou no auditório, tinham dois homens lá: um com cara de mau e o outro com cara de bonzinho. Eles fizeram perguntas relacionadas à parte acadêmica da faculdade, da parte administrativa e da estrutura física. Eu respondi que a faculdade tinha que amadurecer em alguns aspectos administrativos, mas que o aspecto acadêmico se sobrepunha a qualquer problema administrativo, que era realmente muito bom. Um aluno falou, inclusive, que os professores vinham dar as aulas com paixão, e isso foi muito bacana. Com relação à infraestrutura, tinha um aluno que estava com a perna quebrada. Ele disse que a faculdade tinha rampas que facilitavam seu acesso de um lugar para outro na faculdade. Outro falou dos datashow e do ar condicionado em todas as salas. Mas os caras não são bobos, eles já tinham visto tudo isso. Então, foi isso (ENTREVISTA, DISCENTE).

Conforme os relatos obtidos na entrevista, percebe-se que o praticante é o responsável pela execução das atividades das organizações. A variável praticante corresponde aos indivíduos responsáveis pela execução das microatividades que compõem o ambiente da organização, que possibilitam o sucesso da estratégia estabelecida.

\section{CONCLUSÃO}

O strategizing é uma abordagem teórica que compreende a realização das estratégias por meio da conexão das práxis realizadas pelos praticantes que apresentam tipos de comportamentos orientados pelas práticas sociais (JARZABKOWSKI et al., 2007).

O objetivo geral de verificar como a estratégia é desenvolvida na prática para o reconhecimento de um curso de graduação pelo MEC foi atingido, visto que se constatou que o strategi- 
zing ocorre por meio da interação entre prática, práxis e praticante, que resultou no alcance da nota máxima no reconhecimento do curso de graduação em Administração da instituição estudada. Quanto aos objetivos específicos, este estudo permitiu verificar os elementos contidos no ambiente organizacional, como regras, rotinas e procedimentos que possibilitam uma linguagem padronizada para toda a instituição; identificar, por meio de atividades desempenhadas diariamente, que a promoção entre as estratégias existentes e as particularidades cotidianas favorecem o alcance das metas estabelecidas pela instituição; analisar como os praticantes participam da estratégia como prática. Evidenciou-se que o praticante, por ser o responsável pelas ações diárias da organização, torna-se peça indispensável para sucesso do processo de implementação da estratégia da instituição.

Os resultados encontrados neste estudo destacam a necessidade de um alinhamento entre os três elementos desenvolvidos no trabalho de Jarzabkowski et al. (2007), ressaltam a existência do eixo da gestão ambiental como linha transversal a todo projeto pedagógico dos cursos oferecidos, conforme uma exigência do MEC, visto que esses elementos possibilitam o alcance das metas da empresa. Este estudo oportunizou o conhecimento da estratégia como prática social, por meio das atividades diárias dos praticantes e de sua ação em uma determinada instituição de ensino superior.

Como futura linha de pesquisa, sugere-se o aprofundamento deste estudo em um número maior de instituições, possibilitando um quadro comparativo entre IES de diferentes Estados, com diferentes características regionais. 


\section{REFERÊNCIAS}

BALBASTRE, F. La Autoevaluación Según los Modelos de Gestión de Calidad Total y el Aprendizaje en la Organización: Una Investigación de Carácter Exploratorio. 305 f. 2003. Tese (Doutorado em Administração) Universidad de Valencia, Valencia. 2003

BALOGUN, J.; HUFF, A. S.; JOHNSON, P. Three responses to the methodological challenges of studying strategizing. Journal of Management Studies, v. 40, n. 1, p. 197-224, 2003.

EISENHARDT, K. M. Building theories from case study research. Academy of Management Review, v. 14, n. 4, p. 532-550, 1989.

GODOY, A. S.. Pesquisa qualitativa tipos fundamentais, Revista de administração de Empresas - RAE, São Paulo, v. 35, n. 3, p 20-29 mai./jun. 1995.

GOLSORKHI, D., ROULEAU, L. SEIDL, D. ; VAARA, E. Cambridge Handbook of Strategy as Practice. Cambridge University Press, p. 1-20, 2010.

JARZABKOWSKI, Paula. Strategic practices: an activity theory perspective on continuity and change. Journal of Management Studies, v. 40, n. 1, p. 23-55, 2003.

JARZABKOWSKI, Paula. Strategy as practices: recursive, adaptive and practice-inuse.

Organization studies, v. 25, n.4, p. 489-520, 2004.

JARZABKOWSKI, Paula. Strategy as practice: an activity-based approach. London: Sage Publications, 2005.

JARZABKOWSKI, Paula; BALOGUN, Julia; SEIDL, David. Strategizing: the challenges of a practice perspective. Human Relations, v. 60, n. 5, 2007.

JARZABKWOSKI, P; SPEE, A. P. Strategy-aspractice: A review and future directions for the Field. International Journal of Management Reviews, v.1, n.1, 69-95, 2009.

JOHNSON, Gerry; MELIN, Leif.; WHITTINGTON,
Richard. Guest Editors'Introduction: Micro Strategy and Strategizing: Towards an ActivityBaseView.

Journal of Management Studies, v. 40, n. 1, p. 3-33, 2003.

JOHNSON, C. et al. Introducing the strategy as practice perspective. In: JOHNSON, C. et al. Strategy as practice: research directions and resources. New York: Cambridge, 2007.

LAVARDA, R.; CANET-GINER, M. T.; PERISBONET, F. How middle managers contribute to strategy formation process: connection of strategy processes and strategy practices. Revista de Administração de Empresas, n. 50, v. 4, p. 358-70, 2010.

Legislação de Ensino Superior. Disponível em: http://portal.mec.gov.br/sesu/index.php?opt ion=content\&task=view\&id=764\&ltemid=306 Acesso em 9 jul 2011.

MACHADO; D. D. P. N. Inovação e Cultura Organizacional: Um estudo dos elementos culturais que fazem parte de um ambiente inovador. Tese (Doutorado em Administração) Escola de Administração de empresa de São Paulo da Fundação Getúlio Vargas, São Paulo, 2004.

MACHADO-DA-SILVA, Clóvis; FONSECA, V. S. Da; FERNANDES, B. H. R. Mudanças e estratégia nas organizações: perspectivas cognitivas e institucional. In:

MACIEL, C. O. Estratégia como Prática: Contribuições da Visão Baseada em Atividade (VBA). 3Es - III Encontro de Estudos em Estratégia, São Paulo, 9 a 11 de maio, 2007.

RESE, N; CANHADA, D. I. D.; CASALI, A. M. Estratégia como Prática Social: Reflexões sobre o Papel da Comunicação Organizacional. In: V Encontro de Estudos organizacionais da ANPAD. Belo Horizonte. MG 18 a 20 de junho de 2008.

VIEIRA, M. M. F.; ZOUAIN, D. M. (Org.). Pesquisa 
qualitativa em administração. Rio de Janeiro. Editora FGV, 2004.

WHITTINGTON, R. Learning to Strategise: Problems of Practice. SKOPE Research Paper 20, University of Oxford, Autumn, 2001.

WHITTINGTON, R. Practice perspectives on strategy: unifying and developing a field. Academy of Management Conference Proceedings, Denver, August, 2002.

WHITTINGTON, R. et al. Taking strategy seriouly: responsability and reform for an important social practice. Journal of Management Inquiry. v. 12, n. 4, 2003.

WHITTINGTON, R.; JOHNSON, G.; MELIN, L. The emerging field of strategy practice: some links, a trap, a choice and a confusion. In: EGOS COLLOQUIUM, 2004. Proceedings... Slovenia.

WHITTINGTON, R. Completing the practice turn in strategy research. Organization Studies .vol. 27, N.5 pp.613-634. 2006.

WHITTINGTON. Strategy practice and strategy process: family differences and the sociological eye. Organization Studies, v. 28, n. 10, p. 15751586, 2007.

YIN, R. K. Estudo de caso: planejamento e métodos. 2. ed. Porto Alegre: ArTmed, 2005. 
